\title{
CUERPOS EN COMPOSICIÓN Y MOVIMIENTO \\ Tras los contornos del cuerpo musical
}

\section{Bodies in Composition and Movement Behind the Contours of the Musical Body}

\author{
Lautaro Casa I lau.casa@live.com.ar \\ Irene Rodríguez I irene.rodriguez18@gmail.com \\ Facultad de Bellas Artes. Universidad Nacional de La Plata. Argentina \\ Reseña a Ramiro Mansilla Pons (2018). El que compone no baila. \\ La Plata, Argentina: Papel Cosido. Facultad de Bellas Artes de la \\ Universidad Nacional de La Plata. 164 páginas
}

\begin{abstract}
RESUMEN
A partir del diálogo que surge de la producción poética conjunta entre la danza y la música, el libro El que compone no baila analiza los supuestos, dinámicas y procesos que atraviesan las composiciones vinculadas a la danza contemporánea realizadas en la ciudad de La Plata en el periodo de 2006 a 2018. Desde la composición musical como eje, pero entendiendo la creación como una acción vincular, dialéctica y necesariamente situada, Ramiro Mansilla Pons desarrolla un análisis pormenorizado fruto de su experiencia en la producción interdisciplinar y de la reflexión de los y las protagonistas, que pone en crisis paradigmas anquilosados y reproducidos aún hoy en la práctica musical.
\end{abstract}

\section{PALABRAS CLAVE}

Composición; obra artística; cuerpo; danza contemporánea; interdisciplinaridad
Recibido: 11/2/2019 Aceptado: 13/5/2019

\section{KEYWORDS}

Composition; artistic work; body; contemporary dance; interdisciplinarity 
Una constante en la enseñanza y en el aprendizaje musical atraviesa nuestra idea de cuerpo, el propio, el ajeno. Un cuerpo instrumental, técnico, atomizado, reducido a fracciones funcionales, al dominio de técnicas específicas, mecánicas, reiterativas. Este obstáculo a dominar y sistematizar se nos aparece, a los músicos y a las músicas como un títere, funcional a desarrollar las complejas elucubraciones intelectuales que dan lugar a la composición y la producción musical. Entonces, el eje de la creación se erige a partir de la manipulación de un lenguaje producto de códigos, movimientos y procedimientos puestos en relación con un sentido simbólico y arbitrario, condicionado por las reglas de la sintaxis musical y de una concepción de belleza, propio de la idiosincrasia de una época y una cultura específicas.

En esa brecha entre lo corpóreo y la razón instrumental la balanza se inclina a favor de la composición, y no cualquier composición; la producción realizada exnihilo, autónoma y desinteresada, desenraizada de su propio contexto y aun de las propias particularidades de su gestor. El cuerpo distante, utilitario y funcional se vuelve una extensión del instrumento para llevar a cabo los caprichos de la composición.

Es en esa intersección, cuando los ecos ya se han diluido bastante, donde El que compone no baila hunde sus reflexiones y conduce a las lectoras y los lectores a conjugar los lenguajes de la danza y la música, partiendo del análisis de diferentes cuerpos poéticos, enmarcados en una fracción espacial (la ciudad de La Plata) y temporal (de 2006 a 2018), elegida por su autor Ramiro Mansilla Pons. En un contexto y una perspectiva muy diferentes del que esa enseñanza musical eurocéntrica origina y configura en la concepción del músico y, a su vez, entendiendo el fenómeno artístico en su totalidad, el autor supera la idea de composición autónoma, tan arraigada en la producción musical e, indagando en los distintos procesos, procedimientos, diálogos, rupturas que configuran un espectáculo de danza, da cuenta de la construcción de un cuerpo poético, del trabajo sobre la concepción de un cuerpo vivo.
El tema central de este trabajo hace foco en el diálogo generado y en la relación que se construye entre ambas disciplinas (danza y música) para la elaboración de discursos artísticos en la contemporaneidad. En esa línea, desanda a través de sus capítulos reflexiones propias del autor y de los protagonistas (músicos, coreógrafas, bailarines y bailarinas) acerca de los distintos elementos y procesos que configuran la acción poiética y el cuerpo poético en sí mismo.

Partiendo de los supuestos subyacentes que hacen a la perspectiva de los compositores hacia la danza y la música, el autor problematiza las instancias de diálogo y las estrategias discursivas que se tejen entre compositores y coreógrafos, analiza los términos, los acuerdos y los requisitos que hacen a la producción conjunta del fenómeno artístico analizado.

En su recorrido, Mansilla Pons resalta el carácter necesariamente situado de la producción artística y abarca aspectos propios de la producción, los procedimientos compositivos, como también aspectos vinculados a la difusión, los espacios de promoción y el circuito donde se desplazan las obras citadas. A su vez, el autor resalta la posibilidad de extrapolar estos componentes al análisis de otras producciones, de contextos más amplios y/o familiares en lo que se refiere a la práctica artística multidisciplinar (poniendo en caso la semejanza y trazando paralelismos con la relación música-teatro/ música-video y otras disciplinas artísticas).

Eludiendo los compartimentos estancos, el libro analiza la construcción dialéctica de las producciones musicales vinculadas a la danza, entendiendo que no solo el lenguaje artístico, la poiética y la construcción metafórica aúnen ambas disciplinas, sino, también, la corporalidad, la identidad de los actores y de los espacios que la configuran. Así, el cuerpo de los músicos y las músicas es considerado no en su razón instrumental de ejecutantes únicamente sino como entidades poéticas de la producción; los ruidos, las voces, voluntarias e involuntarias de bailarines y bailarinas son consideradas en la producción 
musical. A su vez, la intención del discurso dancístico (propuesto muchas veces a priori por coreógrafas y coreógrafos, bailarinas y bailarines) propone a la música, a la compositora o al compositor en su elaboración ciertos aspectos que la determinan en mayor o menor nivel y, así, esta misma relación puede darse a la inversa. El autor concluye:

\footnotetext{
[...] hemos observado que, luego de esa primera instancia (una propuesta a priori de material generalmente coreográfico), el proceso creativo se caracteriza por ser, con relación a la danza, colaborativo y reciproco. Asimismo, hemos visto que los modos más habituales de generar materiales son la improvisación, la referencialidad al contenido temático de la obra y la imitación de las particularidades del movimiento coreográfico, pero que también es posible recurrir a materiales extramusicales que pueden o no ser explicitados en la composición (Mansilla Pons, 2018, p. 154).
}

Estas consideraciones superan la idea de funciones subordinadas, específicas y ponen el cuerpo, las ideas y la acción a trabajar en forma conjunta. Al margen de la fidelidad analítica, que se desprende de la propia experiencia del autor y de sus posicionamientos teóricos, el libro no solo enriquece en términos teóricos sino que abre un universo práctico, plausible de ser abordado y desanda formas compositivas, circuitos de trabajo y porque no, posibilidades de inserción laboral, que la lógica del corpus musical occidental insiste en invisibilizar tras el velo de la artificiosa autonomía de la producción musical y la distancia ermitaña del compositor.

\section{REFERENCIA}

Mansilla Pons, R. (2018). El que compone no baila. La Plata, Argentina: Papel Cosido. Facultad de Bellas Artes de la Universidad Nacional de La Plata. 